\title{
O COTIDIANO DAS RELAÇÕES AMOROSAS - ENTRE DESAFIOS E AMADURECIMENTOS
}

Resenha do livro 0 curso do Amor, de Alain Botton.

Botton, A. (2017). 0 curso do Amor. Rio de Janeiro: Intrínseca.

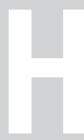

oje em dia é possível encontrar vários filmes e livros com foco nas relações amorosas e que nos embarcam em uma pluralidade de sentimentos, contextos e reflexões. Entre eles, é possível encontrarmos alguns com os quais possamos nos identificar mais ou menos, dependendo de nossas histórias de vida e preferências pessoais. Quando se trata de casais heteroafetivos, o livro O curso do amor, de Alain Botton, pode gerar uma série de identificações ao retratar o início de um relacionamento e os longos anos de seu desdobramento. Além disso, é possível dizer que esta obra se destaca com reflexões sobre o amor romântico e os relacionamentos contemporâneos. $\mathrm{O}$ autor nos leva a considerar o desenvolvimento do amor no curso das vidas, se é só mais um sentimento, se é uma essência ou uma habilidade que precisa ser desenvolvida e experimentada, e sobre quais seriam as diferentes formas de vivê-lo.

Em outras palavras, o livro de Alain de Botton apresenta o curso, na metáfora do autor, de uma relação amorosa desde suas fases iniciais até momentos mais avançados de constituição de família. Nesse curso, a narrativa leva o leitor ou leitora a caminhar pelas dificuldades e os aprendizados presentes em diferentes fases do relacionamento. Nesse sentido, o livro se divide em cinco partes: Romantismo, Sempre depois, Filhos, Adultez e Além do Romantismo. Através dessas fases, o autor descreve o processo vivido por Rabih e Kirsten, casal protagonista da trama, desde o momento em que se conhecem até quando formam um casal, uma família, criam filhos e, então, lidam com as limitações das escolhas da vida.

Diante da leitura desse livro, foi possível reparar vários elementos presentes no trabalho clínico com casais, tais como: atração, afeto, brigas, sexualidade, intimidade, traição, acordos, parentalidade, comunicação e a transgeracionalidade. Por conta da riqueza com que o livro trata essas questões contextualizadas na vida de um casal, essa resenha se propõe a realizar um olhar crítico sobre a obra, pensando em como ela pode ajudar os terapeutas de casais ou famílias a compreender melhor o funcionamento do casal e seus papéis frente a esse sistema. Na resenha, nos propomos a considerar o livro como uma metáfora para então pensar no sistema familiar e nas narrativas de amor dentro da clínica psicológica, no atendimento de casais.

\section{A CHEGADA DO CASAL NO CONSULTÓRIO}

Depois de anos juntos e tentando resolver seus problemas e conflitos sozinhos, existe o momento importante e curioso em que o casal protagonista da história
ESTANTE

DE LIVROS

\section{RENATA BIAVA}

Estudante de Graduação em Psicologia na Universidade Federal de Santa Catarina

\section{ALANA DA SILVA LUIZ ANIJAR}

Estudante de Graduação em Psicologia na Universidade Federal de Santa Catarina

\section{JOÃO PAULO KOLTERMANN}

Estudante de Graduação em Psicologia na Universidade Federal de Santa Catarina

\section{ADRIANO BEIRAS}

Professor do Programa de Pós-Graduação e do Departamento de Psicologia da Universidade Federal de Santa Catarina 
toma consciência da necessidade de ajuda terapêutica. Esse momento é marcado por uma briga do casal que resulta em um ato impulsivo e agressivo que os faz decidir finalmente marcar uma consulta.

Inclusive, pensar nesse processo retoma vários elementos presentes no decorrer do livro e que são importantes serem explorados na terapia; como a dimensão da história do casal e de cada um que o compõe. Diante de um processo terapêutico, essa exploração torna-se muito importante para começar a compreender a construção de significados de cada um e os problemas que vem enfrentando. O livro retrata isso muito bem; logo em seu começo aponta como Rabih e Kirsten possuem compreensões e expectativas diferentes sobre o amor romântico. Rabih é descrito como romântico. Desde seus 15, anos apaixona-se com facilidade e busca viver uma história de amor. Já Kirsten, logo nos primeiros encontros, deixa bem claro que não acredita muito nessa história de "felizes para sempre". Histórias sobre as vivências de cada um e do casal aparecem no decorrer do livro e apontam para a construção dos significados deles e de possíveis impactos dessas compreensões para o relacionamento.

Nesse sentido, o livro traz um aspecto muito importante para pensar a prática do psicólogo, especialmente aquele que atende casais. Outro aspecto importante é entender quem teve a iniciativa de buscar a terapia, quem foi a favor ou contra essa atitude e quais são as queixas iniciais. Tudo isso se torna conteúdo a ser trabalhado com o casal e auxilia o terapeuta a entender a dinâmica do mesmo.

\section{AS CRISES}

O livro retrata vários momentos de dificuldades enfrentadas pelo casal, sejam elas pequenas, que vão desde "coisas bobas" (nas palavras do autor) - como a melhor hora para chamar o táxi ou o modelo de copos para comprar para o apartamento novo - até conflitos mais expressivos - como a chegada dos filhos, a divisão das tarefas da casa, o cuidado com os filhos, a frustração com relação às expectativas de carreira, com questões financeiras, com a perda de entes queridos, ou mesmo com traição, incompreensão e insatisfação de um com o outro. Essas crises enfrentadas pelo casal podem ser entendidas como resultado de diferenças de personalidade entre os dois adultos, da mudança entre os diferentes ciclos de vida que a família enfrenta ao longo dos anos, bem como de dificuldades de lidar com diferentes papéis e identidades que a pessoa pode assumir em cada momento da vida.

O autor relata brevemente a história familiar de Rabih e de Kirsten e também como era a vida de ambos como jovens adultos solteiros. Com a formação do novo casal, Kirsten e Rabih se deparam com desafios de criar regras próprias para a sua relação, realinhar seus objetivos pessoais e os do casal, assim como alinhar o relacionamento entre o cônjuge e as famílias de origem de cada um (Carter \& McGoldrick, 1995). Entretanto, em alguns acontecimentos relatados no livro, percebe-se a repetição de padrões ou criação de expectativa sobre relacionamento do casal, que pode ser percebido como heranças de relacionamentos anteriores, como na família de origem de cada um. 


\section{O PROCESSO TERAPÊUTICO}

Depois de pensar no início da psicoterapia e nas crises que o casal enfrentou, é possível pensar, como um todo, no processo terapêutico em si. Esse talvez seja o aspecto menos evidente no livro e um dos aspectos mais delicados a se tratar, afinal, cada perspectiva dentro da psicologia pode ter uma visão ou um caminho diferente para trabalhar com o casal. Ainda assim, o livro permite um olhar e uma reflexão sobre diversos pontos relacionados a esse processo.

No caso, o autor realiza, no livro, uma reflexão sobre a terapia com base na Teoria do Apego (Bretherton, 1992), mas não trata muito profundamente o processo terapêutico em si. Nesse sentido, como não dominamos a teoria trazida pelo autor, partimos de uma base sistêmica (Vasconcellos, 2003) e construcionista social (Brito \& Germano, 2013; Gergen, 2009) para pensar junto ao livro no processo terapêutico desse casal retratado.

Como já apontado, o livro traz muito bem a história do casal e as crises que eles passaram a enfrentar, o que são indícios de alguns dos caminhos que o processo terapêutico pode percorrer. Contudo, a terapia em si pode assumir diferentes focos e ritmos conforme o processo em si e o contexto em que o casal vive, sobretudo ao se considerar, pela perspectiva sistêmica, que a terapia é um processo de coconstrução e de reelaboração da relação. É possível dizer que um dos objetivos do processo terapêutico seria facilitar e ajudar a ambos do casal desenvolver uma melhor comunicação e mais recursos para lidar com as demandas do dia a dia. Inclusive, muitas coisas poderiam vir à tona nas lentes desse processo, entre elas: a comunicação do casal, a compreensão, a traição, as negociações, a posição de cada um com o outro e com as crianças, e as diferenças que eles possuem entre eles, as queixas e a sexualidade. Esses elementos são narrados no livro e dão muitas pistas para pensar no trabalho terapêutico do psicólogo sobre eles.

Afinal, longe de um processo linear, a terapia volta ao passado de cada um sem perder de vista a relação atual. Semelhante ao processo terapêutico, na leitura do livro é possível evidenciar padrões do relacionamento e do posicionamento de ambos que surgem de aspectos transgeracionais e das experiências relacionais de cada um. Ao entender o casal como um sistema, é importante destacar que a relação entre os dois, as dificuldades e as habilidades que surgem fazem parte de um processo recursivo e que implica várias partes do sistema. É notável que o próprio livro retrata - em uma parte - que a terapeuta percebe um padrão curioso que aparece no conflito do casal: Rabih busca conforto e ser tranquilizado, mas sente a esposa fria e distante, reage a isso de forma agressiva, o que leva Kirsten a distanciar-se ainda mais.

Para trabalhar esses padrões relacionais, cabe ao terapeuta recorrer a diferentes ferramentas, como perguntas circulares e reflexivas (Aun et al., 2005) e práticas narrativas (White, 2007) que ajudam a elaborar perguntas sobre os padrões dominantes e ressignificá-los. Pensar em narrativas pode ser uma ajuda para entender a identidade pessoal de cada cônjuge e para reencontrar as potencialidades de cada um para lidar com os desafios.

Outro foco que a terapia podia trabalhar é sobre a construção dos significados dentro da relação do casal. Sobretudo, a terapia pode ser um lugar de 
questionar e rever os significados das coisas e das palavras para cada um (Brito \& Germano, 2013). Inclusive, no que trata da história pessoal de cada um, seria possível utilizar a ferramenta do genograma (Borges, Costa, \& Faria, 2015) para pensar como foram as relações transgeracionais de cada um, e deixar mais claro os padrões das relações familiares e das figuras parentais (Carter \& McGoldrick, 1995). Com o tempo, a terapia poderia se tornar um processo em que o casal teria a oportunidade de rever sua história e suas compreensões, e de conduzir um olhar mais atento sobre o outro e a própria relação, iniciando, assim, um movimento de mudança, melhor comunicação e qualidade de vida para a família.

\section{CONCLUSÃO}

O livro de Alain Botton caracteriza muito bem o ciclo de vida individual e familiar do casal. Seu romance traz elementos e sutilezas que facilmente podem levar a um processo de identificação do leitor ou leitora com os personagens e com o casal descrito no livro. Para o psicólogo/a/ terapeuta, a leitura desse romance permite um mergulho sobre vários aspectos do personagem, como a vida pessoal de cada um e a forma como eles lidam com os relacionamentos íntimos e, então, familiares. Reconhecemos que essa visão sobre o individual e o conjugal que o livro ilustra permite compreender muito bem parte do que é realizado na clínica psicológica e, inclusive, compreender o processo de construção dos significados de cada personagem.

Além disso, por abordar a história de vida individual e a história conjugal do casal, o livro permite reflexões sobre os padrões relacionais de cada um e sobre a importância das relações anteriores para as relações atuais e futuras, bem como a importância das narrativas e a influência dessas em tais relações. Para um psicólogo sistêmico, um olhar sobre a construção dos significados, sobre os padrões relacionais, homeostase e os aspectos transgeracionais é elementar para a prática clínica.

No entanto, é importante um olhar crítico sobre o processo clínico descrito no livro, em que compreensões de causa e feito e olhares deterministas, superados pelo pensamento sistêmico (Vasconcellos, 2003), podem passar despercebidos. Além do mais, ainda que trabalhe os sentimentos dos cônjuges, o processo clínico descrito no livro carece de diálogos mais claros sobre os significados de cada um e sobre processo relacional, que inclui a ressonância (Andolfi, 2003), e que são fundamentais para a prática clínica sistêmica. Dessa forma, indica-se o livro para os psicólogos não como um exemplo de uma prática clínica, mas como uma muito boa ilustração do processo de desenvolvimento do casal, dos papéis conjugais, da elaboração da história individual e, por fim, dos papéis parentais e coparentais.

Por outro lado, a identificação com o livro pode suscitar no leitor ou leitora diversas reflexões sobre sua própria história de vida e sobre sua relação conjugal e familiar, favorecendo e/ou auxiliando em um possível processo terapêutico. Nesse sentido, o livro pode ser indicado para casais em processo terapêutico, sendo que, paralelo às reflexões do livro, o casal poderia elaborar reflexões sobre a própria história e o próprio relacionamento. 


\section{REFERÊNCIAS}

Andolfi, M. (2003). Manual de psicología relacional: La dimensión familiar. Bogotá: Corporación Andolfi González.

Aun, J. G. (2005). Da terapia de família ao atendimento sistêmico à família. In J. G. Aun, M. J. E. Vasconcellos \& S. J. Coelho (Eds.), Atendimento sistêmico de famílias e redes sociais (pp. 16-57). Belo Horizonte: Ophicina de arte \& prosa.

Borges, C. D., Costa, M. M. D., \& Faria, J. G. D. (2015). Genograma e atenção básica à saúde: em busca da integralidade. Psicologia e Saúde, 7(2), 133-141.

Bretherton, I. (1992). The origins of attachment theory: John Bowlby and Mary Ainsworth. Developmental psychology, 28(5), 759.

Brito, R. M. \& Germano, I. M. P. (2013). Terapia narrativa e abordagem colaborativa: contribuições do construcionismo social para a clínica pós-moderna. Nova Perspectiva Sistêmica, 47, 57-73.

Carter, B. \& McGoldrick, M. (1995). As mudanças no ciclo de vida familiar: uma estrutura para. Porto Alegre: Artes Médicas. (Original publicado em 1985)

Gergen, K. J. (2009). Relational being: Beyond self and community. New York: Oxford University Press.

Vasconcellos, M. J. E. (2003). Pensamento sistêmico: o novo paradigma da ciência. Campinas, SP: Papirus Editora.

White, M. (2007). Maps of narrative practice. WW Norton \& Company.

\section{RENATA BIAVA}

Estudante de Graduação em Psicologia na Universidade Federal de Santa Catarina (UFSC), estagiária no Serviço de Atenção Psicológica da UFSC (SAPSI), em Terapia de Casais e Famílias.

Email: re_biava@hotmail.com

\section{ALANA DA SILVA LUIZ ANIJAR}

Estudante de Graduação em Psicologia na Universidade Federal de Santa Catarina (UFSC), estagiária no Serviço de Atenção Psicológica da UFSC (SAPSI), em Terapia de Casais e Famílias.

Email: alana.anijar@gmail.com

\section{JOÃO PAULO KOLTERMANN}

Estudante de Graduação em Psicologia na Universidade Federal de Santa Catarina (UFSC), estagiário no Serviço de Atenção Psicológica da UFSC (SAPSI), em Terapia de Casais e Famílias.

Email:jpjohnn@hotmail.com

\section{ADRIANO BEIRAS}

Professor do Programa de Pós-Graduação e do Departamento de Psicologia da UFSC. Supervisor acadêmico de estágios em Psicologia Clínica no SAPSI, com ênfase em Terapia de Casais e Famílias.

Email: adriano.beiras@ufsc.br 